Article

\title{
Policy Mobilities and the China Model: Pairing Aid Policy in Xinjiang
}

\author{
Tao Song ${ }^{1,2}$, Weidong Liu ${ }^{1}$, Zhigao Liu ${ }^{1}$ and Yeerken Wuzhati ${ }^{1, *}$ \\ 1 Key Laboratory of Regional Sustainable Development Modeling, Institute of Geographic Sciences and \\ Natural Resource Research, CAS, Beijing 100101, China \\ 2 The Collaborative Innovation Center of the Geographical Environment and Frontier Development in \\ Southwest China, Kunming 650500, China \\ * Correspondence: yeek@igsnrr.ac.cn; Tel.: +86-13401093397
}

Received: 21 May 2019; Accepted: 17 June 2019; Published: 26 June 2019

check for updates

\begin{abstract}
This paper seeks to make a contribution to on-going debates about how to conceptualize the "China model" by emphasizing the top-down regional coordination strategies of China in the context of policy mobilities. The notion of policy mobilities is a hot issue through which to analyze how successful political ideas are often mobilized, imitated, adapted, and reused in new places by various actors through learning the global "best" experiences. However, policy mobilities should be employed as a frame within a specific political-economy context and the "institutional geometries", especially in China which is characterized by centralization of state power and impressive economic growth recently. In this paper, we argue that the case of pairing aid policy in China, in which diffused policy ideas regarding advanced development initiatives are transferred and adopted in relatively underdeveloped areas, serves as a key part of the China model to balance regional development. Drawing on a case study of pairing aid policy in Xinjiang, the paper explores the ways in which the advanced industries, cadres, and investments from 19 developed coastal provinces or cities were mobilized by the state power network: (1) Transferring cadres and technicians from developed areas to directly work in Xinjiang temporally; (2) mobilizing the industrial policy package to attract labor-intensive and resource-oriented firms located in the industrial zones of Xinjiang; and (3) mobilizing a part of fiscal investments from donating areas to expand recipients' direct investments. By doing this, we illustrate how higher-level authority can develop more state powers to transfer regional cadres, capital, and projects from developed areas to less developed ones, as well as how mobilized policies can be entrepreneurially adopted and flexibly mutated in the context of various local conditions.
\end{abstract}

Keywords: regional sustainability; pairing aid policy; policy mobility; Xinjiang; China

\section{Introduction}

Since the 1980s, China's high-speed economic growth with relatively stable social conditions has attracted growing international attention, especially in the context of the global economic crisis starting in 2008, which has caused a generally sluggish economic environment in Europe and the United States, as well as big ups and downs in the Russian economy. The "China model" made its debut in the mainstream economic-political lexicon in 2004, stemming from the "Beijing consensus" [1], denoting an alternative economic development model to the "Washington consensus" with its advocacy of market-friendly policies. As China has become an increasingly important global economic power and global governance actor, the "China model" has been gaining more and more attention from political, economic, and cultural perspectives. Firstly, what makes the China model intriguing is not the duration of the communists' rule per se, but the manner combining an authoritarian regime, especially the 
regionally-decentralized authoritarianism, with market-preserving federalism [2]. Secondly, economic decentralization contributes to China's impressive performance through market economic reforms. Thirdly, Chinese leaders have heralded Confucianism, the core value in the ancient tributary system, for building a harmonious world while pursuing economic profits [3]. An obsession with seeing the China model as a whole interior homogeneity unit has for a long time overshadowed the increasing regional divergences in the large-scale, multi-ethnic country. In fact, the top-down coordinated development between regions is an important component of the China model.

China, as a centralized nation, boasts a long tradition of implementing preferential policies for inland and minority-dominated border areas as a way to close the regional gaps between them and advanced regions (e.g., transferring some budgets from advanced regions in Qing dynasty (called “协饷” in Chinese)). Since the Opening-Up Policy was put forward in 1978, China has undergone skyrocketing economic growth, largely driven by the coastal regions, leading to increasing regional inequalities, particularly shown as the inland-coastal disparities (also known as western-eastern divergence). China's western regions, especially the borderlands such as Xinjiang, Tibet, and Inner Mongolia, are strategic regions. These regions scatter across a vast diverse landscape with minority groups, abundant resources, and an under-developed economy, hence the call for leveraging different strategic policies. For this reason, Chinese central government has been making various efforts to accelerate Chinese western development. For example, the "Go West" policy was worked out to solve the ecological problems and improve infrastructure in Chinese borderland regions. Moreover, the regional coordination policies, including the pairing aid policy, were employed to bring new industries, capital, and cadres to relatively less developed regions, and to remove and diminish barriers to smooth mobility of commodities, staff, and capital to relatively less developed regions.

The pairing aid policy, (“对口支援” in Chinese), was initiated by the Chinese Central Government in the 1950s to help economically under-developed areas. Later on, this policy was expanded to three patterns corresponding to three different objectives respectively (i.e., for economic development of the minority-inhabited border areas, for temporary aid to grand infrastructure construction projects, and for disaster relief and recovery). Despite its different objectives, the pairing aid policy is generally characterized by the central state's domination and regional state and local enterprises' involvement. It is a comprehensive and long-term assistance policy for the minority-inhabited areas, such as Xinjiang and Tibet, involving the flows of cadres, projects, and funds, with the ultimate goal to accelerate the economic development and improve the social stability in ethnic minority areas.

After World War II, one of the important development issues concerning both developing and developed countries, especially the nations with a large geographical area, was to reduce regional disparities and promote the economic growth of less developed areas. Many efforts were made, including the use of the growth pole strategy [4], emphasizing preferential geographic location to form economic agglomeration by supporting economic activities in these regions. However, since the 1980s, globalization-oriented economic competitions come into being with local managers scanning the globe for new and better strategies to cope with their local problems [5], thus leading to more serious imbalance between different regions. Local governments could be regarded as entrepreneurs, by not only attracting global technologies, capital, and labor forces, but also by creatively learning the institutional system. One of the important measures is policy learning globally. Basically, there are two types of development policy innovation: "learning by doing" and "learning global "best", [6]. The former is a time-consuming and endogenous learning process, while the latter is a time-saving and exogenous process by transferring policies [7]. Therefore, policy mobility across boundaries has become an increasingly important strategy to balance regional development by deploying transposable policies in conjunction with footloose capital.

In the neoliberal context, policies are more often seen as practices which are to be chosen from the global arena, to then be adapted and implemented to cultivate competition-oriented and business-friendly institutions [8,9].Today, the "fast-policy" regimes are characterized by pragmatic borrowing of policies that have been worked out by several agencies, including mayors, NGOs, 
and talents, who constitute a relational network at the local and supra-local level, without an emphasis on regional coordination and the top-down governance of central government. The debate on policy mobilities has been rooted in the neoliberalism-oriented development philosophy. In the tide of globalization, marketization, and decentralization, horizontal policy learning could be regarded as a significant regional development power, thus leading to fiercer competitions in different regions [10-13]. However, the central government in China, characterized by authoritarianism, has strong controlling powers in many ways. In addition to such Anglo-Saxon strategic policies as central transfer payment, regional development planning, and so on, the pairing aid policy is widely deployed to accelerate the economic development of border areas and other less developed areas. So, the questions arise whether the theory of policy mobilities could be taken as an important frame to analyze the Chinese regional strategies for regional harmonious coordination, which also constitutes the China Model, and whether it is quite unique when compared to the major case studies analyzed in the literature?

In such a background, this article examines policy mobilities critical to the Chinese pairing aid policy, taking Xinjiang as the case study area. A conjuncture of specific political, socio-economic, and institutional processes, both internal and external, underlines the case of pairing aid policy in China as an assemblage of advanced mobilizing policies. Xinjiang is of strategic significance for China in national security, resource supply, and national integration as well, especially in the context of its vulnerability to violence, sporadically, by ethnic separatists. At the same time, the pairing aid policy in Xinjiang has a history of more than 20 years and will be a highlight as a site for regional sustainable policy experimentation and diversify the empirical scope for observing the field of policies mobility. This paper aims to further substantiate the concept of policy mobility by capturing the Chinese political-economic context for the pairing aid policy, but also interpret the "China model" by emphasizing coordinated Chinese regional development policies, instead of researching a single coastal advanced place, such as the Suzhou model or Wenzhou model. Therefore, in this paper, the China model is best understood as a complete whole unit made of multiple, complex, interrelated patterns, characterized by regional coordination of advanced and less developed regions, defying any definition which reduces it to a single model.

In this article, the Chinese pairing aid policy is discussed in detail in four sections. In the first section, we outline the key debates on policy mobilities in the field of human geography, and explore how these topics assist geographers to conquer regional or urban unbalanced development. We also systematically review the pairing aid policies in China since 1950, and illustrate that the policy development is the result of mobilizing policy learned from Chinese coastal regions to accelerate Chinese western development. In the second section, drawing on the theoretical perspective of burgeoning policy mobilities, a case study of pairing aid policy in Xinjiang is empirically analyzed, with regards to the spatial characteristics, modes, and effectiveness of pairing aid policy. Finally, conclusions and discussions are made accordingly.

This paper draws on seven years of participant observation of Xinjiang industrial projects by the authors in their role as Chinese central and local government planning consultants, and a recent round of semi-structured and open-ended interviews in Xinjiang conducted in 2015, 2017, and early 2019. Interviews with more than 10 officials in Chinese central ministries, including Chinese National Development and Reform Commission, etc., were conducted. More than 30 senior local officials working in bureaus of Development and Reform Commission, Scientific management, urban planning, commerce and business and 40 pairing aid cadres were interviewed. The interviews were normally conducted at the interviewees' workplaces, and the length of each interview varied from 45 to 60 minutes. All interviewees were asked about their knowledge of the status and challenges of development in Xinjiang, as well as related experiences of pairing aid policies. We conducted the fieldwork in more than 10 industrial parks of Xinjiang, and randomly spoke to visitors, enterprise managers, and ethnic inhabitants. In addition to fieldwork materials, the data used in the analyses also include government policy documents (e.g., five-year plans, regional master plans, policy strategic plans) and statistical yearbooks. 


\section{Understanding Chinese Pairing Aid Policy Beyond the Policy Mobilities Approach}

\subsection{Policy Mobilities in the Context of Neoliberalism}

In the context of globalization, regional or municipal decision makers strategize about the best ways to attract the creative class, most potential industry, or become the "smartest", "greenest", "most vibrant" place, thus empowering particular policy models, regimes, and constituencies through appeals to perceived success [14]. Thus "policy mobility" becomes a heated topic in geographical, political, and economic literatures. Different from the concept of "policy transfer", which refers to the transfer processes by intersections of society, politics/governance, and space, and often puts emphasis on the national scale in political science, the notion of "policy mobilities" have been employed recently by geographers as a frame to analyze these geographies of "assemblages, movements, and mutations", characterized by a concern for the actors, practices, and representations that affect the (re)production, adoption, and travel of policies, and the best practice models across space and time. Policies transferred need to be understood not as discrete territories but, rather, as unbounded, dynamic, relational assemblages [15].

In general, the policy mobilities approach orchestrates new forms of assembling, transferring, and mutating policies in threefold. Firstly, academics in the field of policy mobilities flesh out our understanding of multi-scale mobilizing policies, not just such spatial binaries as global/local, far/near ones. The relational network of global, state, and local factors shape the policy flows. Even social nodes, sites, or infrastructures will accelerate the sharing of policies, for example, hotels, stations, conference centers, resorts, galleries, and global cities [16]. Secondly, the state actors, at various scales, still play a crucial role in shaping geographies of knowledge encounter, persuasion, and motivation. Simultaneously, territorial embeddedness should never be forgotten when the transferring policies move and mutate. Thirdly, regional or urban models with "best practices" in business, culture, transport, education, or other aspects are origins of mobilizing policies. Elements of policy model, such as capital, regimes, and technicians affect the adoption of specific policy models by other places.

This significant and growing literature in this vein adopts a post-structural approach, epitomizing the "assemblage" of cadres, agents, calculative practices, and knowledge involved in the transferring, adoption, and reception of policy ideas $[17,18]$. This approach is insightful on the travels, learning, and mutations of particular policies in case studies within political-economy contexts and the "institutional geometries" [19]. One can develop a better understanding of how "the actions and choices of one [state] affect another" [20]. Moreover, such an approach makes it possible to study comparatively diffuse and decentralized policy mobilities where similar changes are occurring simultaneously in multiple locations and across traditional policy spheres [21].

\subsection{Profile of Pairing Aid Policy}

The pairing aid (or “对口支援” in Chinese) program stems from the idea that economically advanced provinces and cities facilitate developing counterparts. It started as early as the 1950s. From the 1950s to the early 1960s, Shanghai dispatched tens of thousands of cadres, workers, and intellectuals in the fields of finance, construction, textile, electrics, mechanics, and higher education to Shaanxi, which has played an important role in Shaanxi's economic development and social progress [22].

In 1979, the pairing aid program was officially established by the Chinese central government as a national policy in its No. 52 Central Document. At the "National Working Conference on Frontier Defense" held in April 1979, Ulanhu, the Chief of the Central United Front Work Department delivered a general assembly report titled "All People of the Country Unite and Strive Together to Build a Thriving Frontier and Consolidate Border Defense." In the report, China pledged to increase investments in border and ethnic minority areas and organize inland provinces and municipalities to support these areas. Later on, this policy expanded into three different objectives: for economic development of the 
ethnic-inhabited border areas, for grand infrastructure construction projects, and for disaster relief and recovery.

After decades of practical operations, China's central government has accumulated rich experience in applying the pairing aid idea by mobilizing the whole country. The representative example of pairing aid for grand infrastructure construction is the relocation of the huge population affected by the Three Gorges Dam from the early 1990s until the 2000s, in which 22 provinces were involved. The pairing aid program supporting the Sichuan earthquake relief and recovery in 2008 was another trial of this idea and showed its advantages in post-disaster reconstruction work.

\subsection{Pairing Aid Policy as an Assemblage of Advanced Practices' Mobilities in the Chinese Context}

In this paper, our concern is to explore how emergent geographies of policy are "made up", how they are socially constructed and spatially constituted in the Chinese context, which resonates with study on the theory of "policy mobilities", the processes of assemblage, mobilization, and mutation of policies [17]. Our argument is that state-mediated policy mobilization is a new phenomenon which highlights the state power network in the context of Chinese local government entrepreneurship. Again, this is not a singular analysis within a fixed frame, but in the networks of economic, sociological, and institutional frames. Transferring policies are assemblages of mobile pieces of expertise, capital and industrial regulations, institutional capacities, etc. An assemblage is a whole of some sort that expresses some identity and claims a territory [23]. With this in mind, we argue that three types of policy elements can be theoretically mobilized within the relevance of the policy mobilities framework: (1) Advanced expertise from agencies, (2) direct capital flows led by state powers, and (3) projects based on national or private firms. Therefore, this paper seeks to theorize how state powers matter through adopting, transferring, and mutating these three different but interrelated types of elements. In doing so, the paper extends this theoretical framework of policy mobilities to the domain of regional coordination policies in the context of the China model, showing how this is a fruitful way to trace the heterogeneity of neoliberal processes across geographical landscapes.

\subsubsection{Advanced Expertise from Agents}

The transfer agents are vital to the study of policy making [24]. As for the pairing aid policy, both cadres and professional technicians will be engaged in spinning off advanced expertise, as Figure 1 shows. To be specific, all kinds of expertise (e.g., "tacit" and "explicit" knowledge) are insourced from such policy actors, as technicians, government official, think tanks, and consultancies [25]. In order to learn more about these "off-the-shelf" policies, policy actors are not conceptualized as lone learners, but as embodied members of epistemic, expert, and practice communities [26]. Circuits of policy knowledge shape and are shaped by social connections made by actors who sometimes sat at a distance-over email, or by reading documents describing policies in other places, or "policy tourism", or via mediating expert consultants who offer knowledge in easily consumable, sellable, and moveable packages. In general, field agents with constitutionally-granted status were empowered to educate, emulate, imitate, and persuade policies characterized by the fundamentally social—practical, interpersonal, institutionally embedded-yet fluid, to address everything from welfare/workfare and poverty [26].

\subsubsection{Direct Capital Flows Led by State Powers}

The policies and initiatives to attract capital flows are crucial parts of mobilizing policy assemblages. Competition between jurisdictions is a prominent mechanism driving the mobility of certain policies. This dynamic is often associated with economic policies formulated to develop market advantage or attract scarce-but-mobile capital, such as lowering taxes, ameliorating investment risk to attract global investments, or making exports competitive. The private-sector are enticed by the potential for future capital accumulation, with their presence legitimized by arguments that they will bring increased private-sector commitment and funding as well as their efficiency, creativity, and understanding of the 
market [27]. As for a communist-led country like China, state power plays a crucial role in transferring development resources, such as capital and investment, to balance regional development. As for the pairing aid policy, capital flows from advanced areas in the form of governments' fiscal transfer payment triggers private investments for their accumulated capital.

\subsubsection{Projects Based on National or Private Firms}

Projects and ideas coming from external sources were framed, transferred, and implemented by actors in many different institutional ways. In some sense, the developmentalism of East Asian states which, unlike their Western counterparts, was characterized by the legitimacy gained not only from the democratic support of the civil society, but also from a series of successful "development" projects. These various projects include ambitious industrial development projects, which serve as the main outlet of pairing aid policy, for less developed localities in China [28], urban redevelopment projects, as key to the vitalization of the construction industries, culture, and the positive legacies of megaprojects, such as the Olympics to drive the urban transformation of Barcelona [29], the community development projects, such as business improvement districts [30]. Especially such megaprojects as hosting the Olympics or Commonwealth Games would help regions, or cities (e.g., Manchester) to be firmly (re)connected into the global economy by providing an unprecedented global platform on which to promote a positive image of itself as well as to encourage gentrifiers, investors, and tourists from elsewhere to the city [31].

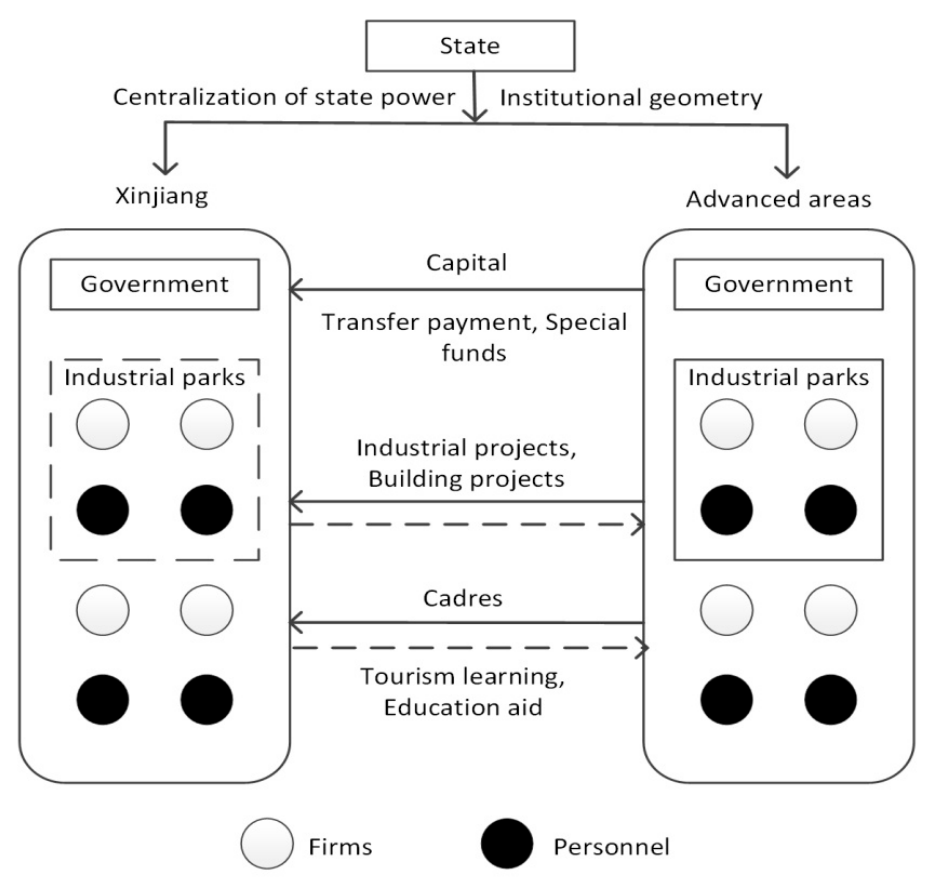

Figure 1. Framework of the pairing aid policy as an assemble of advanced mobilized policies in the Chinese context.

\subsection{China Model: Multi-Level Governance under the Hierarchy of Party-State Governance (Top-Down Mechanism)}

The pairing aid policy illustrates how higher-level authority can develop more state powers to transfer regional cadres, capital, and projects from advanced areas to relatively underdeveloped regions, as well as how mobilized policies can be entrepreneurially adopted and flexibly mutated in the context of various local conditions. In this section, the Xinjiang case is generalized to explain the top-down mechanism in mobilizing advanced policies and inspiring regional entrepreneurism by highlighting three primary agents. 
The first is the dominant role of the central government, especially the party-state mechanism, which holds the final administrative power and orchestrates institutional geometry for the pairing aid policy, as shown in Figure 1. Whether the state power has been decentralized since the opening-up policy in 1978 is a hot topic of debate. However, the case of pairing aid policy in Xinjiang proves the conclusion drawn by some scholars that even at a time when China's economy has been modernized, its political system remains authoritarian by nature with power concentrated in the hands of the Communist Party, and its leaders, who are still powerful in allocating resources and policies. Under the mandatory policy announced by the Chairman of the Communist Party of China, the local governments of 19 economically-developed eastern provinces are given more territory spaces in Xinjiang to mobilize their successful policies, deploy their entrepreneurship, and fulfill central requirements, with the main goal being to boost Xinjiang's development. The case of Xinjiang also shows that post-Mao urban entrepreneurialism is in transformation-from locally-initiated territorial competition in the 1980s to upper-level government coordination and regional cooperation in the 21st century [28].

Personal job promotion serves as the main momentum to deploy mobile advanced policies under the control of the central government. The change of the official name and upgrade in formal relations cannot be implemented without approval by the state [32]. The case of pairing aid policy in Xinjiang illustrates that pairing aid cadres can not only get promoted directly for their cross-posting experience in Xinjiang, but they also draw attention of upper-level government, which will finally lead to promotion. In particular, pairing aid cadres will be evaluated by a series of indicators, including hard indicators, such as GDP, fiscal revenue, net income growth per capita, etc., and soft indicators that are for the reference of overall performances. In this way the state utilizes cadres' personal promotion as an incentive to promote mobilizing advanced "best practice" policies.

The second key agent is provincial governments who, on one hand, exert significant state powers to integrate provincial cadres and policies and mobilize them to paring counterparts in Xinjiang. On the other hand, they also help local firms to expand their production and market territories to Xinjiang. For the former, many provinces have built up pairing aid offices within the provincial government to issue pairing aid policies, including selecting pairing aid cadres from each city, searching for industrial projects in Xinjiang, and implementing pairing aid budgets, etc. Regarding the latter, provincial governments combine the state and market forces by organizing project promotion conferences, seminars, industrial associations in pairing aid areas for the purpose of assisting local firms to expand their industrial chains and territories by pursuing new land sites and market pools.

Thirdly, local governments could serve as development promoters with the pairing aid of their counterparts in advanced areas. However, due to the harsh natural conditions, mostly ethnic-inhabited and shortage of human capital, Xinjiang is characterized by inadequate entrepreneurship and an unfavorable environment for firm growth. Access to greater capital and technicians was hampered by the lack of banking facilities and investors. Very few private firms have survived and been competitive with state-owned enterprises. After cadres and capital are directly transferred from advanced areas, the local governments in Xinjiang serve as an entrepreneurship enabler or promoter in advancing activities and arrangements that help nurture a favorable environment for the growth of firms regardless of their ownership types [28]. Industrial parks by pairing aid regions epitomize the dynamics transplanted from advanced areas, by competing for investment through pro-business policies. Local officials looked beyond individual firms to create favorable conditions for broad-based and sustained growth.

Since the 2000 's, many provincial governments, as well as the central government of China, have adopted the "between-region pairing assistance (BRPA)" policy of assigning responsibilities to the local leaders of developed cities for certain performances in more under-developed areas. In addition, the central government and certain provincial governments have also implemented the "inter-regional cadre transfer (IRCT)" policy to promote developed city officials with excellent performance to higher posts in less developed areas, even though these newly-posted leaders had no connection to these areas before. These measures cast local entrepreneurial government officials in a new role, namely 
making them carriers of local development knowledge as well as transferors of local development resources to facilitate development of less developed areas.

\section{Pairing Aid Policy in Xinjiang, China}

\subsection{Pairing Aid Policy within the Concern of the Stability Security Paradigm in the Case of Xinjiang}

The Xinjiang Uyghur Autonomous Region, which comprises roughly one-sixth of China's land area (1.6649 million square $\mathrm{km}$ ), is strategically significant due to its position on the country's periphery, where China adjoins Central Asia. In the 1940s, Owen Lattimore portrayed Xinjiang as holding a pivotal position, a "new center of gravity" in Asia between the great power politics of China, the Soviet Union, India, and the Moslem Middle East, as shown in Figure 2 [33]. Xinjiang is a pivotal area not only due to its abundance of salt, gold, and jade, and its substantial coal, oil, gas reserves and deposits, but also for its multi-ethnic demographic structure. Taking advantage of its abundant natural resources and being supported by China's western development policy and pairing aid policy, Xinjiang has achieved rapid economic development and rise of average per capita income for urban and rural residents during the past decade. However, Xinjiang has also witnessed the decline of both import and export value of cargo since 2010, as shown in Table 1. This decline might be explained by the weakening currencies, slowing growth, and slumping demands of Russia and countries in Central Asia, as the main destinations of Xinjiang's foreign trade. It was also plagued by a great deal of turmoil, thus maintaining stability in Xinjiang has always been the top priority for both national and local states at all levels.

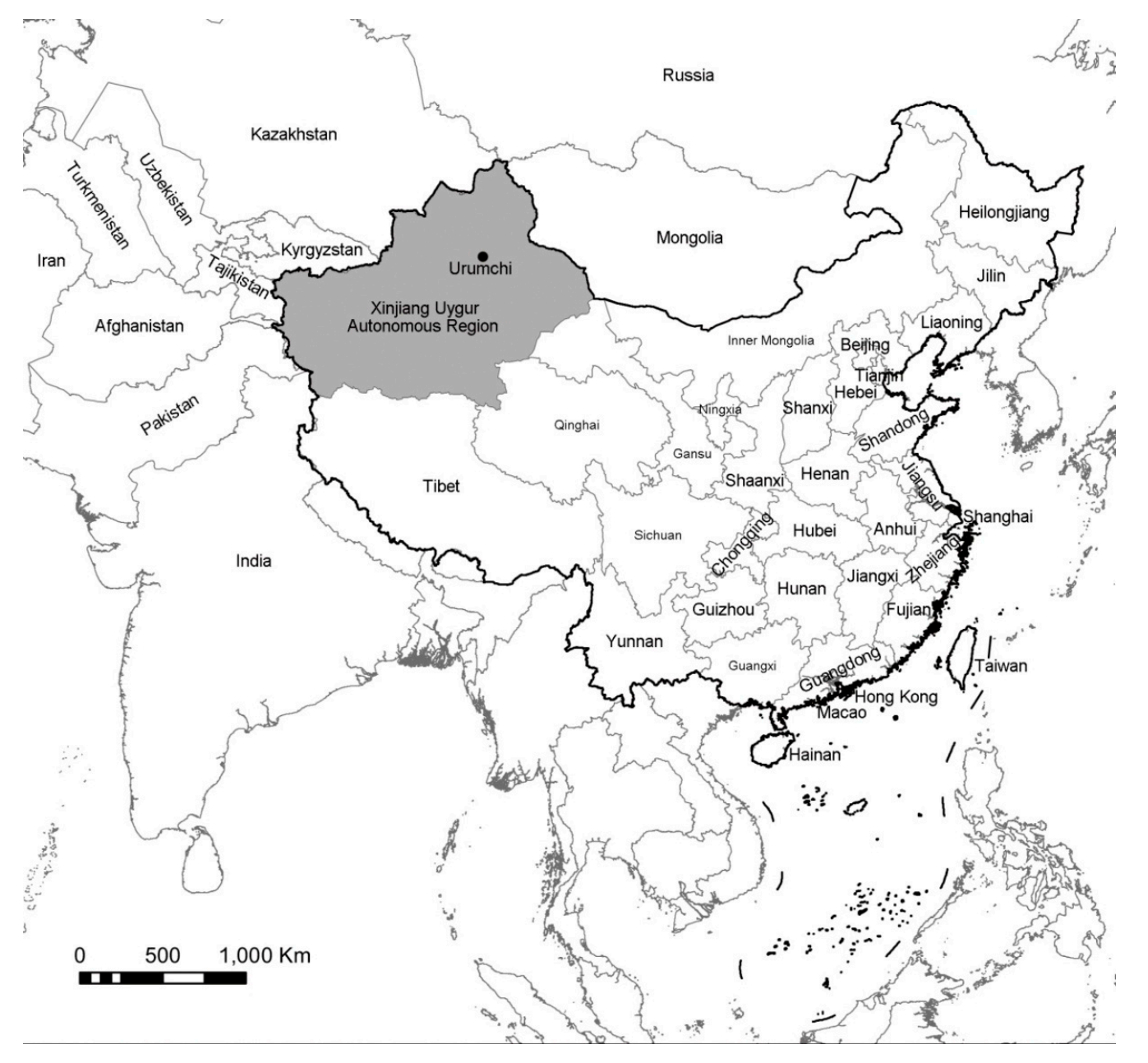

Figure 2. Location of Xinjiang, China. 
Table 1. Socio-economic and demographic profile of Xinjiang.

\begin{tabular}{|c|c|c|c|c|c|c|c|}
\hline \multirow{2}{*}{ Indicators } & & \multicolumn{2}{|c|}{2000} & \multicolumn{2}{|c|}{2010} & \multicolumn{2}{|c|}{2017} \\
\hline & & Xinjiang & $\%$ of China & Xinjiang & $\%$ of China & Xinjiang & \% of China \\
\hline Population (million persons) & & 19.3 & 1.5 & 21.85 & 1.63 & 24.4 & 1.76 \\
\hline & Primary sector & 28.8 & 2.0 & 107.861 & 2.67 & 169.1 & 2.58 \\
\hline & Secondary sector & 58.7 & 1.3 & 253.369 & 1.35 & 429.2 & 1.28 \\
\hline & Tertiary sector & 49 & 1.2 & 180.651 & 1.04 & 493.7 & 1.16 \\
\hline Fixed asset investment (billion yuan) & & 61 & 1.9 & 342.32 & 1.23 & 1179.6 & 1.84 \\
\hline $\begin{array}{c}\text { Per capita income of urban residents } \\
\text { (yuan) }\end{array}$ & & 5645 & 89.89 & 13,644 & 71.40 & $26,274.66$ & 84.22 \\
\hline $\begin{array}{c}\text { Per capita net income of rural residents } \\
\text { (yuan) }\end{array}$ & & 1618 & 71.81 & 4643 & 78.44 & 9425.08 & 82.52 \\
\hline
\end{tabular}

Sources: Guo, 2015a; Xinjiang Bureau of Statistics (2001, 2011, and 2017); National Bureau of Statistics (2001, 2011, and 2017).

The major strategic object of pairing aid policy in Xinjiang would be to facilitate the security and stability of the Chinese border areas, featuring the remoteness from national capital and multi-ethnicity, by marshaling its economic power. It had been characterized by China pursuing its national stability-security objectives for accelerating the economic development of the ethnic-inhabited border areas, which could be traced back to 1776 Qing dynasty, when the central government had allocated two million to three million taels of silver annually (called “协饷” in Chinese) from Chinese inland areas to support economic and military expenses of Xinjiang.

The modern pairing aid policy in Xinjiang was embarked on in the 1979, when Ulanhu, the Chief of the Central United Front Work Department, proposed to implement the pairing aid policy to ethnic-inhabited border areas at the "National Working Conference on Frontier Defense". Since then, Jiangsu Province was assigned to implement the pairing aid policy with Xinjiang. Later on, Shanghai and Shandong became the pairing counterparts of Xinjiang in the 1980s and 1990s, respectively.

In this paper, we argue that this pairing aid policy in Xinjiang could be located within the state systematic project of harmonizing frontiers, including: (1) Transferring cadres and technical professionals from economically advanced areas to directly work in Xinjiang temporally; (2) mobilizing the various favorable industrial policy packages, for example, fiscal and in-kind incentives, to attract labor-intensive and resource-oriented firms located in industrial zones in Xinjiang; and (3) mobilizing a part of fiscal investments from donating areas to expand recipients' direct investments. The pairing aid policy would be incomplete without contextualizing the evolution of three functions:

In the beginning, the pairing aid policy in Xinjiang was narrowed dawn to transferring cadres from coastal provinces. In March 1996, President Jiang Zemin presided over the National meeting of the Communist Party of China on the Xinjiang's stability work, and issued the policy to cultivate a large number of cadres who love to woke in border areas and correctly implement the Party's ethnic policies Xinjiang, which trigged the boom of "pairing aid policy in Xinjiang". In 2002, Hami City and Huocheng County in Xinjiang were issued as the pilot cities to appoint municipal party's chairman from pairing aid counterparts. Three years later, Aksu City, Shule County, and Hotan City were added to the pilot cities. Since the onset of pairing aid policy in Xinjiang in the 1970s, the state had assigned, transferred, or encouraged over 800,000 intellectuals and technical professionals from inland regions to work in Xinjiang.

In 2005, the China's Central Committee adjusted its pairing aid policy in Xinjiang, and issued the document No.15, which highlighted the vital significance of both the cadre aid and economic counterpart supports to the four prefectures and corps in southern Xinjiang. It led to more actors engaged in this round of pairing aid policy, including not only seven provinces and cities, such as Beijing, but also 15 key state-owned enterprises, such as China Yangtze Three Gorges Project Development Corporation.

The onset of 2010 brought about the actual transition of pairing aid policy in Xinjiang by combining transferring cadres, industrial projects, and fiscal investments. The National Conference on Xinjiang debuted in 2010, which was held to secure Xinjiang's social stability and economic momentum. 
In this conference, over 19 more developed provinces and municipalities, including Beijing, Shanghai, Guangdong, Zhejiang, etc., had paired up with and provided aid for various prefectures and cities in Xinjiang in relevant fields, as shown in Figure 3. Since then, the pairing aid policy in Xinjiang has been institutionalized in all forms of cadres' aid, industrial projects, as well as fiscal investment.

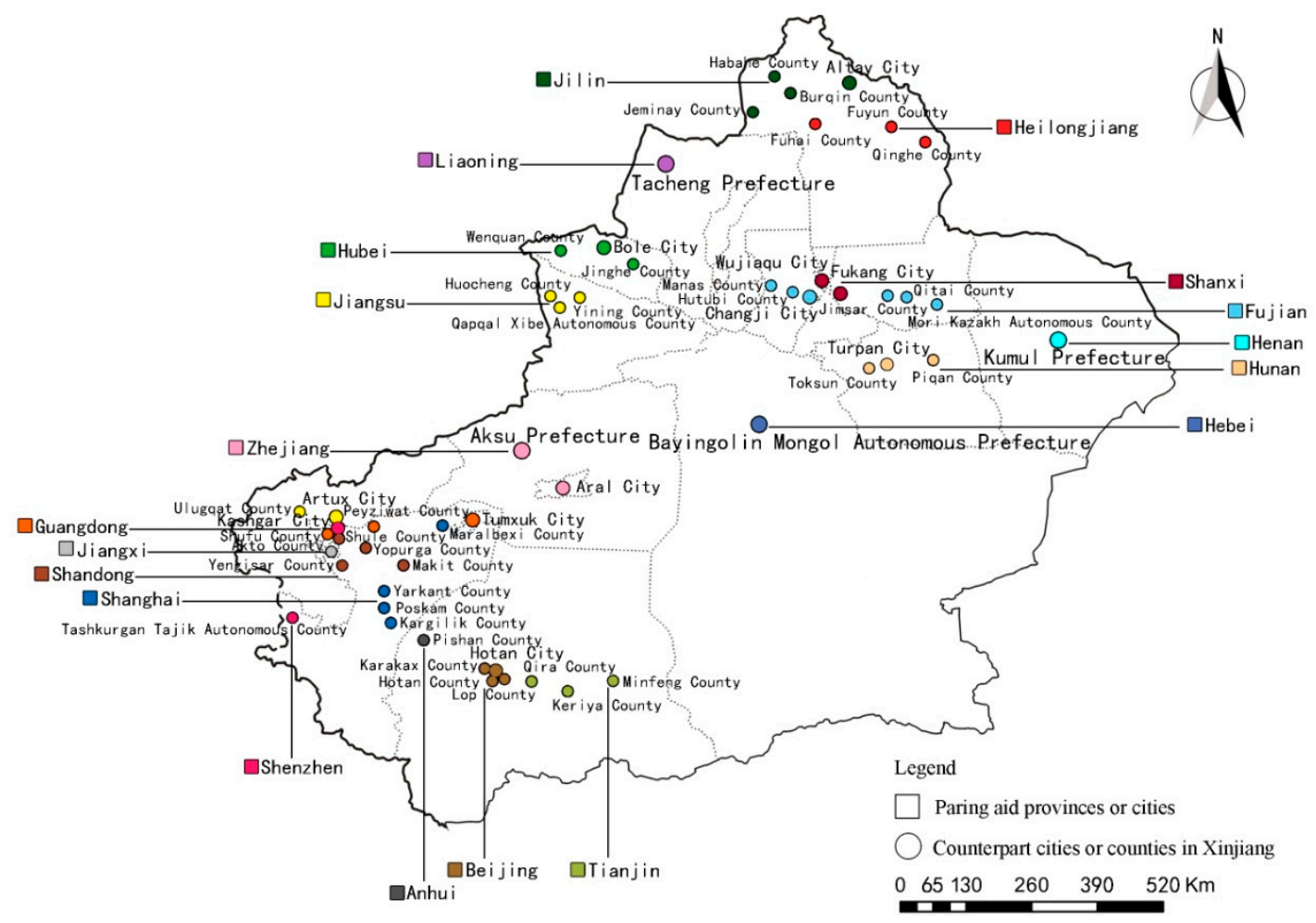

Figure 3. The 19 pairing aid provinces and municipalities since 2010.

Up to date, pairing aid policy in Xinjiang has gradually been institutionalized as a significant means to approach Xinjiang's stability-security paradigm for China's central government. It has been seen that Xinjiang's development was also accelerated by the transplantation of policies from coastal open areas through the delivering of national and local statecraft, in all ways of allocating resources, including human capital and financial capital. According to the thirteenth Five-Year (2016-2020) Plan for Pairing Aid Policy in Xinjiang, promulgated by the Central Government, the governments at all levels across various regions, departments, and industries are committed to establish pairing aid offices to coordinate the allocation of aid resources, also required is the fixed proportion of annual financial budget in coastal developed regions (for example, three thousandths of the financial budget in Henan Province and six thousandths of the financial budget in Beijing since 2011) to distribute economic growth more evenly and secure border areas. The remainder of the article will discuss the pairing aid policy in Xinjiang in detail, one by one, as follows.

\subsection{Mobilizing Cadres from Advanced Areas}

The pairing aid policy was in need of various regulatory, market, and technical professionals; therefore, strengthening talents' mobility was the core of the pairing aid policy by the Aid-Xinjiang Cadres Program (AXCP, “援疆干部” in Chinese). In the 1996 conference on Xinjiang, chaired by Zemin Jiang, the Chairman of Chinese Communist Party, the Chinese central government embarked on the AXCP by selecting more than 200 veteran cadres from seven provinces (i.e., Beijing, Tianjin, Shanghai, Zhejiang, Jiangsu, Shandong, and Henan) and national ministries to work in seven prefectures and 17 institutions in Xinjiang. Since 1997, the central government has assigned eight batches of more than 7000 cadres and technicians in total from national ministries and 19 provinces to work in Xinjiang. 
The Aid-Xinjiang cadres are divided into two categories: One involves those who perform public functions in a political or bureaucratic capacity and will stay in their new posts in Xinjiang for three years. They will get promoted in the bureaucratic system after the pairing aid experiences. This category is similar to the posts of government officials or civil servants in other countries. The other category includes those who hold clerical positions but formally fall under the official nomenclature list (e.g., teachers, technicians, managers). Cadres in this category will stay in Xinjiang for one and a half years. For instance, in the seventh batch of AXCP (2013), 753 people were party and government cadres, accounting for $30 \%$ of the total, while the larger part was made up by professional and technical cadres (1736 people), accounting for $68 \%$ of the total [34].

Such policy as AXCP is effective in political terms (i.e., imposing central mandates on local areas) and in transferring knowledge, including codified knowledge (i.e., spread of agriculture, livestock, irrigation technologies) and tacit knowledge (governance networking, entrepreneurship, as well as advanced industry-oriented strategies). Codified knowledge is often transferred through written and oral materials, while tacit knowledge can be picked up by peer-to-peer learning within partnership and friendly contexts. Although it is difficult to gauge their impacts directly, knowledge will be diffused, adopted, as well as adapted over time.

Tacit knowledge transferred by cadres is significant in improving Xinjiang's local business environments. We interviewed pairing aid cadre representatives about impacts of AXCP on the development of Xinjiang. They mentioned the progress in creating business-friendly environments (i.e., with reduced bureaucracies in business or commercial departments) due to the improved ambience shaped by transferring talents. Although the Chinese western region, especially Xinjiang, is lagging far behind the coastal regions in attracting talent and foreign direct investment (FDI), and creating a less bureaucratic environment, the transferred veteran cadres are more adept at building a favorable business environment than their local counterparts and helping shape local government entrepreneurship.

The AXCP program also included educational tours designed for local cadres to learn from pairing areas. Local cadres who sought to learn from advanced areas were selected and funded by China's centralized personnel management system. These educational tours, focusing on educated and technical staff, involved the activities and conferences highlighting the best practices in agriculture, transport, investments, etc., through which policy knowledge was transferred into Xinjiang. The learning and adaptation process was facilitated for paired teachers, technicians, and managers in Xinjiang on a one-to-one basis. These provided frameworks and settings in and through which policy mobilities operate. All of these conclusions were confirmed by semi-structured interviews with key participants.

Educational aiding policy is a fundamental part of pairing aid policy. Education gaps and minority conflicts hinder the policy mobilities, largely due to the messy encounters between local elicits and global context in Xinjiang characterized by many ethnic groups, such as the Uygurs, Hans, Kazaks, Mongolians, Huis, etc. Cadres sent to support Xinjiang often have connections with experts and scholars in fields such as education, hygiene, science, technology, and so on, who are able to give lectures in Xinjiang. Teachers are selected to expand bilingual school education further into its rural and pasturing areas, giving more children access to advanced knowledge. For example, China is experiencing an "asymmetric" decentralization that can be described as an "economic decentralization to the local" along with "political centralization under the party." In the context of asymmetric decentralization, the enterprising local leaders have to meet the requirements under certain performance indicators to be considered for promotion. AXCP is one of the most important ones for getting promotion and subsidies for cadres in remote and border areas. AXCP enables non-local officials to be assigned to higher posts in Xinjiang. This could be regarded as the spillover effect of mobilizing policy for cadres, with the transferring of advanced knowledge and resources to facilitate the development of Xinjiang.

\subsection{Mobilities of Industry-Oriented Policies}

Development zone is regarded as a large-scale spatial transformation policy for attracting industrial firms and land expansion in Chinese local entrepreneurialism since economic reform in the late 1970. 
Most pairing aid policies have initiated local industrial development in Xinjiang from building up or renewing industrial zones. The pairing assistance for industrial zones is epitomized by the Jiangsu Province paradigm of aiding the economic development zone in Horgos in Xinjiang. Drawing upon the remarkable experiences of Suzhou Industrial Park, including strong government and effective governance, fully authorized management system, and the increase in infrastructure investment efforts, the Jiangsu government guided the state-owned capital investment of 1.5 billion Yuan to Horgos from Suzhou Industrial Park. While Suzhou Industrial Park became a powerful agent of industrial revitalization, Horgos tends to receive strong supports from private firms (e.g., Yulong Group from Suzhou investing 800 million Yuan to build a comprehensive bonded logistics center in the Horgos, and Yun-peng Suzhou Real Estate enterprise investing 800 million to build a global trade center). All of these flagship investment projects from Jiangsu are framed due to the path-dependent development of a strong local state [35] and "best practices" demonstration in Suzhou Industrial Park.

Mobile industrial policies travel almost as a complete "package" [26] in order to activate related industrial development in Xinjiang, which also serves as "political achievements" for pairing aid cadres. The policy "package" for attracting labor-intensive and resource-oriented industries, which could combine the advantages of being rich in labor and resources in Xinjiang, includes "special economic development zones' policy in Kashi, Yining, etc.", free land policy for desert and waste and plots, and preferential tax policy for pairing assistance firms which relocate their whole factories into Xinjiang. All of these novel discourses, learned from pairing aid counterparts, seek to legitimizing industrial projects, and to follow the "best practices" of land finance in coastal advanced areas. This was actually a win-win scenario. To use the local metaphor, with the help of advanced areas in building new nests (such as the development zone with quality infrastructure and management systems), Xinjiang was able to attract potential inward investors. For its pairing aid counterparts, the successful relocation of some older factories will be a successful political achievement.

It is notable that pairing aid cadres play a key role in bridging pairing assist firms with local policies. Cadres from advanced areas have increased the opportunities to lobby for firms' interests in expanding existing industrial chain and utilities at the local level. Priority policies tailored to meet the needs of pairing aid firms were outlined by the pairing aid cadres in special industries, such as textile and agriculture pairing aid planning for Zhejiang, Guangdong provinces, etc. Until 2015, textile enterprises from Zhejiang province have completed an investment of 3.5 billion Yuan to Xinjiang in textile and garment production, accounting for two thirds of the regional textile production capacity [36]. As for agricultural pairing aid policy, related cadres promoted the paring of production and marketing between Zhejiang and Xinjiang Province through administrative intervention. The Zhejiang Agricultural Development Group, a state owned enterprise in Zhejiang, took charge of selling fruits grown in Aksu to 10 cities and more than 100 markets in Zhejiang. A total of $28 \%$ of fruits grown in Aksu, Xinjiang were sold to Zhejiang in 2015.

\subsection{Direct Top-Down Investment Policy}

Chinese regional development is primarily driven by direct capital investment policy. Constrained by the slow economic development and limited fiscal revenues, it is unlikely that Xinjiang can speed up its economic and social development on its own. Indeed, the transferring of investment policies directly from advanced areas is a case in point. Under the "Strengthening the work on Xinjiang pairing aid policy in 2012", announced by the Chinese central government, each area is requested to invest $0.3 \%-0.6 \%$ of its total local finance budget to its pairing aid counterpart in Xinjiang. In addition, the funding for pairing assistance in Xinjiang is expected to grow by $8 \%$ every year since 2012 . With central pairing aid policy, counterparts in Xinjiang will be seen as "enclaves" to adopt investments from advanced regions.

The implementation of mobile investment policies was adapted and mutated to improve the livelihood of minority people and crack the problem of poverty, instead of simply copying the policy of investment in grand infrastructure construction projects. According to the pairing aid 
investment policy from the central government, top priorities should be placed on the projects affecting people's well-being in allocating capital. Until June 2013, there have been a total of 1925 pairing aid arrangements of livelihood projects from all 19 provinces and municipalities, accounting for $61.7 \%$ of the total. More than $70 \%$ of the investment funds were allocated for the construction of people's livelihood, for example, in the fields of safe drinking water, bilingual education, affordable housing, etc., while more than $95 \%$ of the funds had been arranged to minority-inhabited areas. Under this new mandatory arrangement of the pairing fiscal program by central government, Xinjiang, as a local-level power, was able to gain new momentum to ameliorate minorities' livelihoods.

\subsection{Operations and Effectiveness of Mobilized Policies in Xinjiang}

Policies will mutate in the course of their travels from one jurisdiction to another, Even the "same" policies tend to be associated with different effects in different places, by virtue of their embeddedness in, and interactions with, local economic, social, and institutional environments [26]. As for the case of Xinjiang, we argue that Xinjiang has gained plenty of cadres, capital, and projects through the effective administrative orders by state power; however, without a combination with local initiatives, it is only the "transfusion of blood" instead of a "hematogenesis" form of sustainable development.

\subsubsection{Limited Help of Industrial Projects to Local Areas}

It is obvious that major pairing-assistance industrial projects are focused on resource-oriented or people-intensive industries (e.g., petrochemical, textile and garment, agricultural industries, etc.). If they are not well embedded in the local context, these projects will become the "enclaved" only located in Xinjiang, without contributing much to local tax and employment. Under the pairing aid policies directed by state power, Xinjiang shows a direction for Chinese urban entrepreneurialism characterized by territorial competition driven by different regions' paring assistance schemes. Firstly, the paring assistance schemes of various regions pursued for almost homogeneous industrial projects in similar industrial zones, especially for the heavy chemical industry. On the one hand, it will continue to intensify competitions within the region; on the other hand, the heavy chemical industry has relatively limited demands for labor, thus it cannot effectively increase the employment opportunities and income there. Secondly, constrained by the shortage of related talents and their long distance from the market, most pairing assistance enterprises have difficulties in supporting industrial chains, thus are unable to make significant contributions to the economic development of the recipient areas.

\subsubsection{Unstable (Periodical) Transferring Mechanism of Talents from Advanced Areas}

Each pairing assistance unit and aid-Xinjiang cadre have helped Xinjiang's related areas and departments formulate and improve industrial and local development plans, actively raised funds for the implementation of assistance projects in Xinjiang, and have introduced investments from China's other regions since the initiation of the aid-Tibet work. However, we also continue to see that it is not a stable mechanism for the selection of cadres and staff, even arbitrary to some extent. One group of aid-Xinjiang cadres have to work in Xinjiang for only three years, thus policy coherence would be affected by transferring various groups of cadres. Additionally, it was noted that there is a "mismatch" between less access of really needed technicians from pairing aid enterprises and full of local relatively less educated labors in Xinjiang. Thus, it is urgent that an upper-level government talent tank and coordination mechanism should be built up to bridge the talent gap between talent output and local labors.

\subsubsection{Projects of "Hematogenesis" from "Transfusion of Blood"}

With the metaphor of "transfusion of blood" vs. "hematogenesis", we argue that most pairing aid initiatives were investment-and construction-oriented through fiscal transfer payments (the "transfusion of blood" mode of pairing aid policy), without enough considerations on triggering local economic development by cultivating industrial development (the "hematogenesis" mode of pairing aid policy). 
Pairing aid capital is mostly prioritized for construction projects and the renovation of infrastructure in the mode of "transfusion of blood". However, Xinjiang is a vast territory with many scattered minorities. It is so hard to gauge the impacts of the pairing aid capital in infrastructure, but the interviews with local cadres reveal that some invested construction projects were not perfectly implemented, without fully absorbing local ethnic culture and livelihood. Moreover, most of these building projects were undertaken by donors from advanced areas, with little impact on related local firms. In contrast, projects of "hematogenesis" need more engagement of local dwellers, enterprise managers, etc.

\section{Conclusions}

The "China model", combining authoritarianism and a market economy, serves as the Chinese governing concept that explains the dramatic rise of China's economy, military strength, and geopolitical standing. However, a good deal of debates occurs in the economic realm, without focusing on the Chinese regional coordination, especially the development of border areas. The Chinese government has taken many measures to promote the economic development of the border areas, of which the pairing aid policy plays a key role in improving the trajectory of economic and political developments for less developed areas by transferring not only advanced cadres, capital, and industrial projects but also institutional foundations. Taking Xinjiang as the case study area, this paper systematically studied the nature, agents, and institutional framework of pairing aid policy. Correspondingly, the policy mobilities approach was deployed, which focuses on the issues of policy transfer and transformation, entailing the relational interpenetration of policy-making sites and activities, spawning phenomena like global policy "models", transnational knowledge networks, and innovatory forms of audit, evaluation, and advocacy.

In this paper we examined the process by which diffused policy ideas regarding advanced development initiatives were transferred and adopted in under-developed areas, as the case of pairing aid policy in China demonstrated. Through delineating the flows of cadres, capital, and projects from advanced areas to Xinjiang, the case study illustrates how the mobilizing policies led by a state-centered mechanism serve as effective tools to spur motivation and transfer entrepreneurship for changes in underdeveloped areas. We also continue seeing that institutional efforts made by state governments can be a critical determining mechanism in shaping the policy flow landscape. While substantial work on the mobilizing policy literature has enriched our understanding of urban races for modeling policies in attracting talents, activities, and knowledge, this paper sheds light on this field by showing that the wider institutionalized political-economic geography should never be neglected. Widely diffusing policies never move equally in other geographic locations in the context of competitive globalization. State powers embedded in mobilizing policies endorsed by upper-level government play a crucial role in transferring talent, knowledge, and project flows to activate the local transformation of urban entrepreneurialism. This is not to fall into a literal understanding of the simple transfer of abstract policies among rational policymakers, but rather to recognize that policy mobilities should be understood as the state-sponsored remaking process of regions into institutional, historical, and spatial territories.

Since the initiation of a new round of aid-Xinjiang policy, marked by two national conferences on Xinjiang from 2010 to 2014, over 19 better-developed provinces and municipalities, including Beijing, Shanghai, Guangdong, Zhejiang, etc., have paired up with and provided aid for various prefectures and cities in Xinjiang in relevant fields with fruitful results. Since plenty of policy resources have been successfully transplanted in Xinjiang, it is still difficult to assess the effectiveness of pairing aid policy. However, it is clear from the above discussion that the effects of pairing aid policy were discounted due to lack of overall management from provincial state governments and inactive engagement of local entrepreneurship. This paper, therefore, provides empirical evidences for the claim that mobilizing policies should fully take into account geographical locality and activate local entrepreneurship, instead of using the simple "transfusion of blood" mode of pairing aid policy. The case of Xinjiang illustrates that local geographical conditions and the "fixed" constitutional framework hinder the smooth flow 
of projects, cadres, and capital. It is further shown that the transfer of policies is rarely a process of direct reproduction; instead, policies "mutate and morph" in response to challenges and expectations of the localities involved (Peck and Theodore, 2010b). The application of these ideas, along with our emphasis on multi-level governance empowered by state governments, extends the body of geographical research on mobile policies and local entrepreneurship by highlighting the significance of state powers from the top-down institutional mechanism, as well as reconsidering the importance of local entrepreneurship. This extension of conceptual framework spurs more work on spatial variation of state power and local motivations when policies move and mutate from a to $b$.

More generally, while the pairing aid policy shifting towards the "hematogenesis" mode, from the "transfusion of blood" mode, may be a positive development trend, it is necessary to combine both the local engagement within the bottom-up institutional framework and the planning of the mobilizing resources as a whole from the top-down perspective. The first step toward working together would be to establish ongoing pairing aid workgroups to increase cooperation among various agencies, capital, utilities, and communities, and to share best practices and recognize the nexus. There is also a lot to learn and mutate for local governments, not only in applying the transferred policies as a dynamic adaptation process, but also in creating the best foundation for mobilizing policies of various backgrounds.

While our paper serves as a lens to explore how the pairing aid policy accelerates the relatively less developed regions' development, the efforts of governments should be exerted to combine the mobilizing advanced policies in developed areas with cultivating local vigor. It is evident in our study that mobilizing advanced cadres, projects, and capital from advanced areas can be beneficial for both exporting and importing areas. However, decentralized pairing-assistance resources, along with lack of local engagement, still entail unbalanced regional development in Xinjiang as well as fledging mobilizing policies. Thus, the top-down mechanism of pairing aid policy in China needs deep reflections in several key periods since it was initiated.

There also remains the question of whether the pairing aid policy, stemming from the context of Chinese planned economy, can adapt to China's new development environment, characterized by the market economy. Since the eighteenth National Congress of the Communist Party of China in 2012, the Chinese government has declared that the market mechanism should play a fundamental role. To this end, how do we evaluate the real impact of pairing aid policy on the economic and social development of the less developed areas in China? More case studies are necessary to enrich the research on mobile policies combining the global "best" with local conditions. How to coordinate the visible hand of government and the invisible hand of market economy in order to ensure the development of Chinese borderlands and minority areas is an open question.

Author Contributions: Conceptualization, T.S., W.L. and Z.L.; methodology, Y.W.; software, Y.W.; validation, T.S.; formal analysis, Z.L.; investigation, T.S., W.L., Y.W. and Z.L.; resources, Y.W.; data curation, T.S.; writing-original draft preparation, T.S., Z.L.; writing_-review and editing, T.S.; visualization, Y.W.; supervision, Y.W.; project administration, W.L.; funding acquisition, T.S. and Y.W.

Funding: This research was funded by the National Science Foundation of China [No.41701131, No.41701138, No. 41530751] and the Strategic Priority Research Program (A) of the Chinese Academy of Sciences [No. XDA19040403, No.XDA20010103]. The APC was funded by the National Science Foundation of China [No.41701131, No.41701138].

Conflicts of Interest: The authors declare no conflict of interest.

\section{References}

1. Ramo, J.C. The Beijing Consensus; The Foreign Policy Center: London, UK, 2004.

2. Landry, P.F. Decentralized Authoritarianism in China; Cambridge University Press: New York, NY, USA, 2008.

3. Yang, J. Rethinking the Beijing Consensus: How China responds to crises. Pac. Rev. 2011, 24, 337-356.

4. Darwent, D. Growth poles and growth centers in regional planning-A review. Environ. Plan. 1969, 1, 5-32. [CrossRef] 
5. McCann, E.; Ward, K. Relationality/territoriality: Toward a conceptualization of cities in the world. Geoforum 2010, 41, 175-184. [CrossRef]

6. Bok, R.; Neil, M.C. Geographies of policy knowledge: The state and corporate dimensions of contemporary policy mobilities. Cities 2017, 63, 51-57. [CrossRef]

7. Bok, R. Airports on the move? The policy mobilities of Singapore Changi Airport at home and abroad. Urban Stud. 2015, 52, 2724-2740. [CrossRef]

8. Fraser, N. From discipline to flexibilization? Reading Foucault in the shadow of globalization. Constellations 2003, 10, 160-171. [CrossRef]

9. Peck, J. Geographies of policy: From transfer-diffusion to mobility-mutation. Prog. Hum. Geogr. 2011, 35, 773-797. [CrossRef]

10. Wang, S.; Zhu, A.; Ge, Y.; Liu, Y.; Xue, X. The Spatio-Temporal Evolution of Geo-Economic Relationships between China and ASEAN Countries: Competition or Cooperation? Sustainability 2017, 9, 1064. [CrossRef]

11. He, S.J.; Li, L.Y.; Zhang, Y.; Wang, J. A Small Entrepreneurial City in Action: Policy Mobility, Urban Entrepreneurialism, and Politics of Scale in Jiyuan, China. Int. J. Urban Reg. Res. 2018, 42, 684-702. [CrossRef]

12. Wu, F. Emerging Chinese cities: Implications for global urban studies. Prof. Geogr. 2016, 68, 338-348. [CrossRef]

13. Zhang, J. From Hong Kong's capitalist fundamentals to Singapore's authoritarian governance: The policy mobility of neo-liberalising Shenzhen, China. Urban Stud. 2012, 49, 2853-2871. [CrossRef]

14. Temenos, C.; McCann, E. Geographies of Policy Mobilities. Geogr. Compass 2013, 7, 344-357. [CrossRef]

15. Allen, J.; Cochrane, A. Beyond the Territorial Fix: Regional Assemblages, Politics and Power. Reg. Stud. 2007, 41, 1161-1175. [CrossRef]

16. Cook, I.R.; Ward, K. Conferences, informational infrastructures and mobile policies: The process of getting Sweden ‘BID ready'. Eur. Urban Reg. Stud. 2012, 19, 137-152. [CrossRef]

17. Larner, W.; Laurie, N. Travelling technocrats, embodied knowledges: Globalising privatisation in telecoms and water. Geoforum 2010, 41, 218-226. [CrossRef]

18. McCann, E. Urban policy mobilities and global circuits of knowledge: Toward a research agenda. Ann. Assoc. Am. Geogr. 2011, 101, 107-130. [CrossRef]

19. Brenner, N.; Peck, J.; Theodore, N. Variegated neoliberalization: Geographies, modalities, pathways. Glob. Netw. 2010, 10, 182-222. [CrossRef]

20. Elkins, Z.; Simmons, B.A. On waves, clusters, and diffusion: A conceptual framework. Ann. Am. Acad. Political Soc. Sci. 2005, 598, 33-51. [CrossRef]

21. Geddie, K. Policy mobilities in the race for talent: Competitive state strategies in international student mobility. Trans. Inst. Br. Geogr. 2015, 40, 235-248. [CrossRef]

22. Guo, R.X. Chinese-Style Development in Xinjiang; Elsevier: Amsterdam, The Netherlands, 2015.

23. Wise, J.M. Assemblage. In Gilles Deleuze: Key Concepts; Stivale, C.J., Ed.; McGill-Queen's University Press: Montreal, QC, Canada, 2005; pp. 77-87.

24. McCann, E.; Ward, K. Policy assemblages, mobilities and mutations: Toward a multidisciplinary conversation. Political Stud. Rev. 2012, 10, 325-332. [CrossRef]

25. Goldman, M. Imperial Nature: The World Bank and Struggles for Social Justice in the Age of Globalization; Yale University Press: New Haven, CT, USA, 2005.

26. Peck, J.; Theodore, N. Recombinant workfare, across the Americas: Transnationalizing fast welfare policy. Geoforum 2010, 41, 195-208. [CrossRef]

27. Cochrane, A.; Peck, J.; Tickell, A. Manchester plays games: Exploring the local politics of globalization. Urban Stud. 1996, 33, 1319-1336. [CrossRef]

28. Chien, S.S.; Zhao, L.T. State-Mediated Knowledge Transfer and Resource Mobility: A Case Study of China Local Government Entrepreneurship. Issues Stud. 2015, 51, 39.

29. Cochrane, A.; Ward, K. Guest editorial: Researching the geographies of policy mobility: Confronting the methodological challenges. Environ. Plan. A 2012, 44, 5-12. [CrossRef]

30. Loney, M. Community against Government: The British Community Development Project, 1968-78: A Study of Government Incompetence; Heinemann Educational Books: London, UK, 1983.

31. Cook, I.R.; Ward, K. Trans-urban Networks of Learning, Mega Events and Policy Tourism: The Case of Manchester's Commonwealth and Olympic Games Projects. Urban Stud. 2011, 48, 2519-2535. [CrossRef] 
32. Chung, H. State regulation and China's administrative system: A spatial perspective. China Rev. 2008, 8, 201-230.

33. Lattimore, O. Pivot of Asia: Sinkiang and the Inner Asian Frontiers of China and Russia; Little, Brown: Boston, MA, USA, 1950.

34. Chinese Government Public Information Online. 2015. Available online: http://govinfo.nlc.gov.cn/xjfz/xxgk/ xjwwezzqfzhggwyh/201207/t20120712_2249100.shtml?classid=401 (accessed on 12 January 2017).

35. Stein, C.; Michel, B.; Glasze, G.; Putz, R. Learning from failed policy mobilities: Contradictions, resistances and unintended outcomes in the transfer of "Business Improvement Districts" to Germany. Eur. Urban Reg. Stud. 2015, 17, 1-15. [CrossRef]

36. Statistics Bureau of Xinjiang Uygur Autonomous Region 2001 \& 2011. Available online: http://www.xjtj.gov.cn/ (accessed on 12 January 2017).

(C) 2019 by the authors. Licensee MDPI, Basel, Switzerland. This article is an open access article distributed under the terms and conditions of the Creative Commons Attribution (CC BY) license (http://creativecommons.org/licenses/by/4.0/). 